\title{
Synthesis of High-Affinity, Hydrophobic Monosaccharide Derivatives and Study of Their Interaction with Concanavalin A, the Pea, the Lentil, and Fava Bean Lectins ${ }^{1}$
}

\author{
Duraikkannu Loganathan, Scott E. Osborne, ${ }^{*}$ Gary D. Glick, ${ }^{*}$ and Irwin J. Goldstein ${ }^{2}$ \\ Department of Biological Chemistry and ${ }^{*}$ Department of Chemistry, University of Michigan, Ann Arbor, Michigan 48109
}

Concanavalin $A$ (Con $A$ ) and agglutinins from the pea (PSA), lentil (LCH), and fava bean (VFA) constitute a group of D-mannose/D-glucose binding legume lectins. In addition to their sugar binding specificity, these lectins also contain sites that bind hydrophobic ligands. The present study explores a class of nonpolar binding sites reportedly present adjacent to the carbohydrate binding site in PSA, LCH, and VFA. A series of 2- $O$ and $3-O$-substituted nitrobenzoyl and nitrobenzyl derivatives of methyl $\alpha$-D-glucopyranoside and methyl $\alpha$ D-mannopyranoside were synthesized. Evaluation of their binding to Con A, PSA, LCH, and VFA was carried out by the technique of hapten inhibition of precipitation reaction. The hapten inhibition assay results reveal that the presence of a methyl or methylene group at the $\mathrm{O}-2$ or $\mathrm{O}-3$ position of the sugar is essential for hydrophobic interaction with PSA, LCH, and VFA. The substitution of methyl by nitrobenzyl leads to enhanced binding (1.7-16.7 times for the 2-O-substituted compounds and 7.9-40.5 times for the 3-O-substituted compounds) with the $m$-nitrobenzyl group contributing to maximum binding. A hydrophobic interaction is also involved between Con $A$ and $\boldsymbol{Z}-O$-nitrobenzyl derivatives, resulting in enhanced binding, but the corresponding 3-O-isumers bind poorly due probably to steric reasons. These results may be rationalized on the basis of the recently published X-ray data of Con $A$ and VFA. The nitrobenzyl derivatives, after transformation to their azido analogs, have potential applications in the photoaffinity labeling of these lectins.

1992 Academic Press, Ine.

${ }^{1}$ This research was supported in part by NIH Grant GM 29470 (I.J.G.). ${ }^{2}$ To whom correspondence should be addressed. Fax: (313) 763-4936.
Concanavalin A (Con A) from jack bean (Canavalia ensiformis) and agglutinins from the pea (Pisum sativum, PSA), the lentil (Lens culinaris, LCH), and the fava bean (Vicia faba, VFA) constitute a group of D-mannose/Dglucose binding legume lectins with high protein sequence homology and common carbohydrate binding properties. The molecular structure and carbohydrate binding specificity of these lectins have been extensively studied (1). Whereas Con A consists of four identical subunits, the other lectins are composed of two light $(\alpha)$ and two heavy $(\beta)$ chains. With regard to their carbohydrate binding specificity, all four lectins require the pyranose forms of $\alpha$-D-mannose $/ \alpha$-D-glucose. The hydroxyl groups most critical for Con A binding are those at positions C-3, C4 , and C- 6 and it will tolerate considerable variations at the $\mathrm{C}-2$ position. On the other hand, lectins from the pea, the lentil, and the fava bean require unmodified hydroxyl groups at C-4 and C-6.

The lectins PSA, LCH, and VFA, however, differ significantly from Con $\mathrm{A}$ in binding $3-O$-substituted derivatives of D-mannose/D-glucose. Using the technique of hapten inhibition of hemagglutination, Allen and coworkers showed that the 3-O-methyl and 3-O-benzyl derivatives of glucose are 2-16 times more inhibitory than glucose for the pea, the lentil, and the fava bean lectins but are very poor or noninhibitors of Con A (2). Studies on the inhibition of the precipitation reaction of the pea and lentil lectins with a phosphomannan led to similar

\footnotetext{
${ }^{3}$ Abbreviations used: Con A, the lectin from jack bean (Canavalia ensiformis); PSA, the lectin from the pea (Pisum sativum); LCH, the lectin from the lentil (Lens culinaris); VFA, the lectin from fava bean (Vicia faba); me, methyl; manp, mannopyranoside; glcp, glucopyranoside; PBS, phosphate-buffered saline, $\mathrm{pH}$ 7.2; TLC, thin-layer chromatography; ${ }^{1} \mathrm{H}$ NMR, proton magnetic resonance spectroscopy.
} 
results $(2,3)$. However, the 3 -0-linked disaccharides of glucose, nigerose, and laminaribiose were found to be poor inhibitors of the pea, the lentil, and the fava bean lectins $(2,3)$. On the basis of these results, Allen and co-workers suggested the presence of a hydrophobic area in the sugar binding site of the lectin that interacts with the methyl group of the 3-O-methyl glucose and the methylene (or benzyl) group of 3-O-benzyl glucose. The 3-O-substituted D-mannose derivatives were not examined.

Sites which bind hydrophobic ligands are a common feature of many plant lectins, notably those present in leguminous plant seeds. Several classes of such sites have been described from non- to highly specific. The objective of the present study was to explore a class of nonpolar binding sites adjacent to the carbohydrate binding sites of PSA, LCH, and VFA. In designing the carbohydrate ligands as probes of this hydrophobic site, we kept in mind their potential application as intermediates in the preparation of photoaffinity labels for mapping the nonpolar binding site in these lectins. 'Thus the nitrobenzyl derivatives of methyl $\alpha$-D-man $p$ and methyl $\alpha$-D-glcp were chosen because they could then be transformed to their photoactivable azido derivatives for affinity labeling. In this paper we report the synthesis of the monosaccharide derivatives 5, 6, and 19-30 and evaluation of their binding to Con A, PSA, LCH, and VFA by the technique of hapten inhibition of precipitation.

\section{MATERIALS AND METHODS}

Materials. Methyl $\alpha$-D-mannopyranoside and methyl $\alpha$-D-glucopyranoside were obtained from Pfansteil Laboratories, Inc. (Waukegan, IL). Methyl 4,6-O-benzylidene-( $\alpha$-D)-glucopyranoside (1) and methyl 4,6()-benzylidene- $\alpha$-D-mannopyranoside (2) were prepared by following the literature procedures $(4,5)$. Methyl 2-O-methyl- $\alpha$-D-mannopyranoside (31) and methyl 3-( )-methyl- $\alpha-\mathrm{D}$-mannopyranoside (32) were synthesized according to the procedure of Nashed (6). Benzyl bromide, $m$-nitrobenzyl bromide, $p$-nitrobenzyl bromide, $p$-nitrobenzoyl chloride, imidazole, and 2,4,6-tri(pyridyl)-1,3,5-triazine were from Aldrich (Milwaukee, WI). Acetonitrile was distilled from calcium hydride under $\mathrm{N}_{2}$. Amberlite IR120 ion-exchange resin was purchased from Mallinckrodt Chemical Co. Silica gel $60(70-220$ mesh) was from EM Science (Gibbstown, NJ). Silica gel (32-63 mesh) for (flash) column chromatography was obtained from ICN Biochemicals (Cleveland, $\mathrm{OH}$ ). Glass-backed silica gel 60 plates precoated with a 0.25 -mm-thick layer of kieselgel $60 \mathrm{~F}-254$, for thinlayer chromatography, were obtained from E. Merck (Darmstadt, Germany). Components were visualized by uv quenching ( $254 \mathrm{~nm}$ ) or by staining the plate in ceric ammonium molybdate $(48.0 \mathrm{~g}$ ammonium molybdate and $2.0 \mathrm{~g}$ cerium(II) sulfate in 1 liter of $10 \%$ aqueous sulfuric acid). Con $A$ was purified by the procedure of Agrawal and Goldstein (7). Lectins from the pea and the lentil were purchased from E. Y. Laboratories (San Mateo, CA). Fava bean lectin was kindly provided by Dr. W. J. Peumans of the Catholic University of Leuven, Belgium. Dextran B-1:355 S, Saccharomyces cerevisiae mannan, and Pichia sp. and Hansenula holstii phosphomannans were available from other studies.

Methyl 2-()-(p-nitrobenzoyl)-4,6-()-benzylidene-( $\alpha-1)$-glucopyranoside (3) and methyl 3-0-(p-nitrobenzoyl)-4,6-0-benzylidene-(x-D-glucopyranoside (4). Imidazole $(3.4 \mathrm{~g}, 50 \mathrm{mmol})$ was dissolved in chloroform $(40 \mathrm{ml})$ by stirring and the mixture was cooled to ice-bath temperature. To this solution, $p$-nitrobenzoyl chloride $(25 \mathrm{mmol}$ in $22 \mathrm{ml}$ chloroform) was added dropwise with stirring over 5 min. The reaction mixture was filtered to remove the solid material. Methyl 4,6- $O$-benzylidene- $\alpha$-D-glucopyranoside $(7.1 \mathrm{~g}, 25.2 \mathrm{mmol})$ was added to the filtrate, and the mixture was stirred at reflux for $18 \mathrm{~h}$ and concentrated under reduced pressure. The residue was chromatographed on silica gel using benzene/ethyl acetale $(4 / 1)$ as the eluent. The first fraction crystallized from hexane/ ethyl acetate to give 3 as needles $\left(3.2 \mathrm{~g}, 30 \%\right.$ ), TLC $R_{f} 0.67$ (chloroform/ methanol, 50/1), mp 196-198 $\mathrm{C}$ (Lit. (8) $195-197^{\circ} \mathrm{C}$ ). The second fraction also crystallized from hexane/ethyl acetate to give 4 as needles (2.2 g, 20\%), T'LC $R_{f} 0.61$ (chloroform $/$ methanol, 50/1), mp $233-235^{\circ} \mathrm{C}$ (Lit. (8) $233-235^{\circ} \mathrm{C}$ )

Methyl 2-O-(p-nitrobenzoyl)- $\alpha$-D-glucopyranoside (5). Compound 3 $1215 \mathrm{mg}, 0.5 \mathrm{mmol})$ was suspended in $25 \mathrm{ml}$ of $80 \%$ aqueous acetic acid, stirred at reflux for $3 \mathrm{~h}$, and concentrated to dryness under reduced pressure. Column chromatography on silica gel (chloroform/methanol, $20 / 1$ ) followed by crystallization from hexane/ethyl acetate furnished the title compound $\mathbf{5}$ as needles, TLC $R_{f} 0.26$ (chloroform/methanol, $15 / 1), \operatorname{mp} 166-167^{\circ} \mathrm{C} .{ }^{1} \mathrm{H}$ NMR $\left(500 \mathrm{MHz}_{2} \mathrm{CDCl}_{3}\right.$, and a drop of $\left.\mathrm{CD}_{3} \mathrm{OD}\right)$ ): $\delta 8.31$ and $8.27\left(\mathrm{ABq}, 4 \mathrm{H}, p-\mathrm{NO}_{2} \mathrm{C}_{6} \mathrm{H}_{4}\right), 5.02\left(\mathrm{~d}, 1 \mathrm{H}, J_{1,2}=3.7 \mathrm{~Hz}, \mathrm{H}-1\right)$; $4.94\left(\mathrm{dd}, 1 \mathrm{H}, J_{2,1}=3.7 \mathrm{~Hz}, J_{2,3}=10 \mathrm{~Hz}, \mathrm{H}-2\right) ; 4.10-3.20(\mathrm{~m}, 8 \mathrm{H}, \mathrm{H}-3$, $\mathrm{H}-4, \mathrm{H}-5, \mathrm{H}-6, \mathrm{H}-6$, and $\mathrm{OCH}_{3}$ ); 2.21 (dd, $1 \mathrm{H}, J=4.6$ and $9.5 \mathrm{~Hz}$, $6-\mathrm{OH})$.

Methyl 3-O-(p-nitrobenzoyl)- $\alpha$-D-glucopyranoside (6). Compound 4 ( $215 \mathrm{mg}, 0.5 \mathrm{mmol}$ ) was treated in the same manner as above to obtain the title product 6 as pale yellow needles, TLC $R_{f} 0.33$ (chloroform/ methanol, $15 / 1), \operatorname{mp} 94-95^{\circ} \mathrm{C} .{ }^{1} \mathrm{H}$ NMR $\left(500 \mathrm{MHz}, \mathrm{CICl}_{3}\right): \delta 8.31$ and $8.26\left(\mathrm{ABq}, 4 \mathrm{H}, p-\mathrm{NO}_{2} \mathrm{C}_{6} \mathrm{H}_{4}\right) ; 5.36(\mathrm{t}, 1 \mathrm{H}, J=9.5 \mathrm{~Hz}, \mathrm{H}-3) ; 4.86(\mathrm{~d}, J=$ $3.8 \mathrm{~Hz}, \mathrm{H}-1)$; $3.93-3.74(\mathrm{~m}, 5 \mathrm{H}, \mathrm{H}-2, \mathrm{H}-4, \mathrm{H}-5, \mathrm{H}-6$, and H-6'); 3.50 (s, $\left.3 \mathrm{H}, \mathrm{OCH}_{3}\right) ; 2.51(\mathrm{~d}, 1 \mathrm{H}, J=5.3 \mathrm{~Hz}, 4-\mathrm{OH}) ; 2.14(\mathrm{~d}, 1 \mathrm{H}, J=11.4 \mathrm{~Hz}$, $2-\mathrm{OH}) ; 1.19(\mathrm{dd}, 1 \mathrm{H}, J=5.6$ and $7.1 \mathrm{~Hz}, 6-\mathrm{OH})$.

Typical procedure for the synthesis of methyl 2-(O-(p-nitrobenzyl $)-4,6-$ O-benzylidene- $\alpha-D$-glucopyranoside (9) and methyl 3-O-(p-nitrobenzyl)1,6-O-benzylidene- $\alpha-1)$ glucopyranoside (12). The protected sugar (1) (400 $\mathrm{mg}, 1.4 \mathrm{mmol}$ ) and potassium carbonate (196 $\mathrm{mg}, 1.4 \mathrm{mmol}, 1.0$ eq) were partially dissolved in acetonitrile $(5.7 \mathrm{ml})$ followed by the addition of $p$-nitrobenzyl bromide $(307 \mathrm{mg}, 1.4 \mathrm{mmol})$. The reaction mixture was stirred under $\mathrm{N}_{2}$ overnight at reflux, diluted with ethyl acetate, and washed with $1 \mathrm{M}$ citrate, saturated sodium bicarbonate, and saturated $\mathrm{NaCl}$ solution. The organic layer was dried over $\mathrm{MgSO}_{4}$ and concentrated under reduced pressure to give a white solid. This residue was chromatographed on silica gel (eluting with a $2 / 1$ mixture of petroleum ether/ ethyl acetate) to give methyl 2-O-( $p$-nitrobenzyl)-4,6-O-benzylidene- $\alpha$ D-glucopyranoside $(9)(59 \mathrm{mg}, 10 \%$ yield) and methyl $3-O$ - $(p$-nitrohenzyl)-4,6-O-benzylidene- $(x-D$-glucopyranoside $(12)(71 \mathrm{mg}, 12 \%$ yield) as white solids. TLC ( $33 \%$ ethyl acetate in petroleum ether) $R_{f} 0.33(\mathbf{9})$ $0.20(12), m p 106-107^{\circ} \mathrm{C}(9), 123-125^{\circ} \mathrm{C}(12)$ ' $^{\prime} \mathrm{H}$ NMR data are listed in Table II.

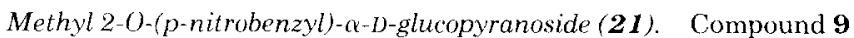
$(35 \mathrm{mg}, 0.084 \mathrm{mmol})$ was dissolved in methanol $(3 \mathrm{ml})$ and to this solution cation-exchange resin ( $\mathrm{IR}-120-\mathrm{H}^{+}, 0.3 \mathrm{~g}$ ) was added. The reaction mix ture was stirred overnight at $30^{\circ} \mathrm{C}$. The methanolic solution was filtered through Whatman filter paper and the filtrate was concentrated under reduced pressure to a syrup. Column chromatography of this syrup on silica gel followed by lyophilization afforded the title compound $(21)$ as a pale yellow powder $(>80 \%)$. TLC (chloroform/methanol, $9 / 1) R_{f}(0.31$, mp $115-116^{\circ} \mathrm{C} .{ }^{1} \mathrm{H}$ NMR data are given in Table III.

Methyl 3-O-(p-nitrobenzyl)-a-D-glucopyranoside (24). Compound 12 $(30 \mathrm{mg}, 0.072 \mathrm{mmol})$ was trcated in the same manner as above to obtain 24 as a pale yellow solid $(90 \%)$. TLC (chloroform/methanol, 9/1) $R_{f}$ $0.39, \mathrm{mp} 109-111^{\circ} \mathrm{C} .{ }^{1} \mathrm{H}$ NMR data are given in Table III.

Methods. Melting points were determined on a MELT-TEMP melting apparatus (Laboratory Devices, Holliston, MA) and are uncorrected. All 'II NMR spectra were recorded on a Bruker AM 300 or AM $360 \mathrm{MHz}$ spectrometer. Spectra were measured at ambient temperature in $\mathrm{CDCl}_{3}$ or $\mathrm{CD}_{3} \mathrm{OD}$ using tetramethylsilane as the internal standard. 


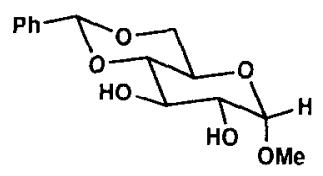

1
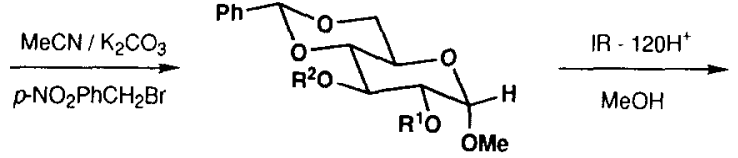

$9 \mathrm{R}^{1}=\mathrm{CH}_{2} p-\mathrm{NO}_{2} \mathrm{Ph}, \mathrm{R}^{2}=\mathrm{H}$

$12 R^{1}=H, R^{2}=\mathrm{CH}_{2} p-\mathrm{NO}_{2} \mathrm{Ph}$

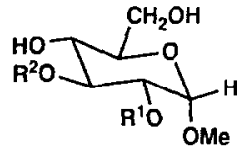

21

24

FIG. 1. Typical reaction scheme.

Mass spectra were recorded on a VG Analytical (70-S) mass spectrometer using ammonia as a reagent in the chemical ionization mode and $p$ nitrobenzyl alcohol as a matrix in the fast atom bombardment mode.

Quantitative precipitation and precipitation inhibition assay. A microprecipitation technique was employed for quantitative precipitation assay (9). Stock solutions of Con $\mathrm{A}(1 \mathrm{mg} / \mathrm{ml})$, the lentil lectin $(5 \mathrm{mg} /$ $\mathrm{ml})$, fava bean lectin $(5 \mathrm{mg} / \mathrm{ml})$, dextran B-1355 S $(2 \mathrm{mg} / \mathrm{ml})$, S. cerevisiae mannan $(1 \mathrm{mg} / \mathrm{ml})$, Pichia sp. phosphomannan $(5 \mathrm{mg} / \mathrm{ml})$, and $H$. holstii phosphomannan $(5 \mathrm{mg} / \mathrm{ml})$ were prepared in phosphate-buffered saline (PBS). In the case of the pea lectin, a stock solution $(2 \mathrm{mg} / \mathrm{ml})$ was prepared in PBS containing $0.1 \mathrm{mM} \mathrm{MnCl}$. The precipitation reaction was conducted by adding Con A $(15 \mu \mathrm{g} / 15 \mu \mathrm{l})$, pea lectin $(60 \mu \mathrm{g} / 30 \mu \mathrm{l})$, lentil lectin $(100 \mu \mathrm{g} / 20 \mu \mathrm{l})$, or fava bean lectin $(50 \mu \mathrm{g} / 10 \mu \mathrm{l})$ to plastic vials $(1.5 \mathrm{ml})$. Varying aliquots of polysaccharide solution were added and the mixtures were adjusted to a final volume of $100 \mu$ using PRS containing $1 \mathrm{M} \mathrm{NaCl}$ solution. In the case of the pea lectin, a PBS solution containing $1 \mathrm{M} \mathrm{NaCl}$ and $0.1 \mathrm{mM} \mathrm{MnCl}_{2}$ was used. The reaction mixtures were kept at room temperature for 2 days and centrifuged $(11,500 \mathrm{rpm}, 10 \mathrm{~min})$ and the supernatant solutions removed. The precipitates were washed three times with $150 \mu \mathrm{l}$ of PBS containing $1 \mathrm{M}$ $\mathrm{NaCl}$. The protein content of the precipitate was determined by Lowry's method (10) using bovine albumin as the standard.

Stock solutions of the hapten standards (methyl $\alpha$-D-manp and methyl $\alpha$-D-glc $p$ ) and monosaccharide derivatives 19-30 were prepared in double-distilled water. Hapten inhibition of the precipitation of lectinpolysaccharide complex was carried out by adding varying aliquots $(0.5-$ $50 \mu \mathrm{l}$ ) of the standard or the monosaccharide derivative $(1-100 \mathrm{mM})$ to the plastic vial and adding an aliquot of lectin solution (same amount

TABLE I

Reaction Yield and Physical Properties of Compounds 7-30

\begin{tabular}{ccccccc}
\hline $\begin{array}{c}\text { Compound } \\
\text { number }\end{array}$ & $\begin{array}{c}\text { Reaction } \\
\text { yield }{ }^{a}(\%)\end{array}$ & TLC $R_{f}$ & mp $\left({ }^{\circ} \mathrm{C}\right)$ & $\begin{array}{c}\text { Compound } \\
\text { number }\end{array}$ & TLC $^{b} R_{f}$ & mp $\left({ }^{\circ} \mathrm{C}\right)$ \\
\hline $\mathbf{7}$ & 40 & $0.42^{c}$ & $110-112$ & $\mathbf{1 9}$ & 0.34 & $119-120$ \\
$\mathbf{8}$ & 12 & 0.27 & $102-103$ & $\mathbf{2 0}$ & 0.32 & Syrup \\
$\mathbf{9}$ & 10 & 0.33 & $106-107$ & $\mathbf{2 1}$ & 0.31 & $115-116$ \\
$\mathbf{1 0}$ & 4 & $0.26^{c}$ & $118-120$ & $\mathbf{2 2}$ & 0.42 & $90-91$ \\
$\mathbf{1 1}$ & 12 & 0.17 & $\mathbf{1 4 9 - 1 5 0}$ & $\mathbf{2 3}$ & 0.40 & Syrup \\
$\mathbf{1 2}$ & 12 & 0.20 & $123-125$ & $\mathbf{2 4}$ & 0.39 & $109-111$ \\
$\mathbf{1 3}$ & 16 & 0.72 & $89-90$ & $\mathbf{2 5}$ & 0.42 & $99-100$ \\
$\mathbf{1 4}$ & 19 & 0.50 & Syrup & $\mathbf{2 6}$ & 0.40 & $95-96$ \\
$\mathbf{1 5}$ & 23 & 0.50 & Syrup & $\mathbf{2 7}$ & 0.39 & $\mathbf{1 1 4 - 1 1 6}$ \\
$\mathbf{1 6}$ & 10 & 0.45 & $98-100$ & $\mathbf{2 8}$ & 0.41 & Syrup \\
$\mathbf{1 7}$ & 20 & 0.29 & Syrup & $\mathbf{2 9}$ & 0.39 & Syrup \\
$\mathbf{1 8}$ & 19 & 0.24 & Syrup & $\mathbf{3 0}$ & 0.40 & $\mathbf{1 3 1 - 1 3 2}$ \\
\hline
\end{tabular}

${ }^{a}$ Yield of isolated pure product.

${ }^{b}$ Chloroform/methanol $(9 / 1)$.

${ }^{c}$ Petrolium ether/ethyl acetate (4/1) and petrolium ether/ethyl acetate (2/1) for 8, 9, and 11-18. as used for the quantitative precipitation) and polysaccharide solution (15 $\mu \mathrm{g} / 7.5 \mu \mathrm{l}$ of dextran 1355 for Con A, $20 \mu \mathrm{g} / 20 \mu \mathrm{l}$ of $S$. cerevisiae mannan for the pea lectin, $80 \mu \mathrm{g} / 16 \mu \mathrm{l}$ of Pichia sp. or $H$. holstii phosphomannan for the lentil lectin, and $10 \mu \mathrm{g} / 5 \mu \mathrm{l}$ of $S$. cerevisiae mannan for fava bean lectin). Incubation of the mixtures, processing, and protein determination of the precipitates were carried out as above for quantitative precipitation experiments.

\section{RESULTS}

Reaction of methyl 4,6-O-benzylidene- $\alpha$-D-glucopyranoside (1) with $N$-benzoyl imidazole in chloroform gave a mixture of methyl 2-O-( $p$-nitrobenzoyl $)-4,6-O$-benzylidene- $\alpha$-D-glucopyranoside (3) and methyl 3-O-( $p$-nitrobenzoyl)-4,6-O-benzylidene- $\alpha$-D-glucopyranoside (4) in 30 and $20 \%$ yields, respectively. The mp and ${ }^{1} \mathrm{NMR}$ data of 3 and 4 agree well with those reported by Ishido and coworkers (8). On stirring a suspension of 3 and $\mathbf{4}$ in $80 \%$ aqueous acetic acid at reflux for $3 \mathrm{~h}$, complete debenzylidenation was effected. The crystalline products 5 and 6 showed a characteristic methine proton signal at $\delta 4.92$ $\left(\mathrm{dd}, J_{2,1}=3.7 \mathrm{~Hz}\right.$ and $\left.J_{2,3}=10 \mathrm{~Hz}, \mathrm{H}-2\right)$ and at $\delta 5.36(\mathrm{t}$, $J=9.5 \mathrm{~Hz}, \mathrm{H}-3$ ), respectively, confirming their structural assignment.

Monoalkylation of methyl 4,6-O-henzylidene- $\alpha$-D-glucopyranoside (1) or methyl 4,6-O-benzylidene- $\alpha$-D-mannopyranoside (2) was carried out in dry acetonitrile at reflux with one equivalent of $\mathrm{K}_{2} \mathrm{CO}_{3}$ using benzyl bromide, $m$-nitrobenzyl bromide, or $p$-nitrobenzyl bromide as the alkylating agent (Fig. 1). Each of these reactions gave a mixture of monoalkylated products in moderate yields that were purified by flash chromatography on a silica gel column. The reaction yields, and $\mathrm{mp}$ data of the monoalkylated products $7-18$ are reported in Table $I$ and their ${ }^{1} \mathrm{H}$ NMR data are listed in Table II. Compound 8 was also analyzed by fast atom bombardment mass spectrometry in the positive ion mode and it showed the expected molecular ion peak at $m / z 418\left[\mathrm{M}+\mathrm{H}^{+}\right]^{+}$.

Debenzylidenation was readily effected by stirring overnight a methanolic solution of each of the compounds 7-18 in the presence of IR-120 $\left(\mathrm{H}^{+}\right.$form) cation-exchange resin. The deprotection in each case was nearly quantitative and the resultant product was purified on silica gel by column chromatography. Table I lists the physical properties of the products $19-30$ and their ${ }^{1} \mathrm{H}$ NMR data are listed in Table III. Additional proof for 
TABLE II

${ }^{1} \mathrm{H}$ NMR Data for $\mathbf{7 - 1 8 ^ { a }}$

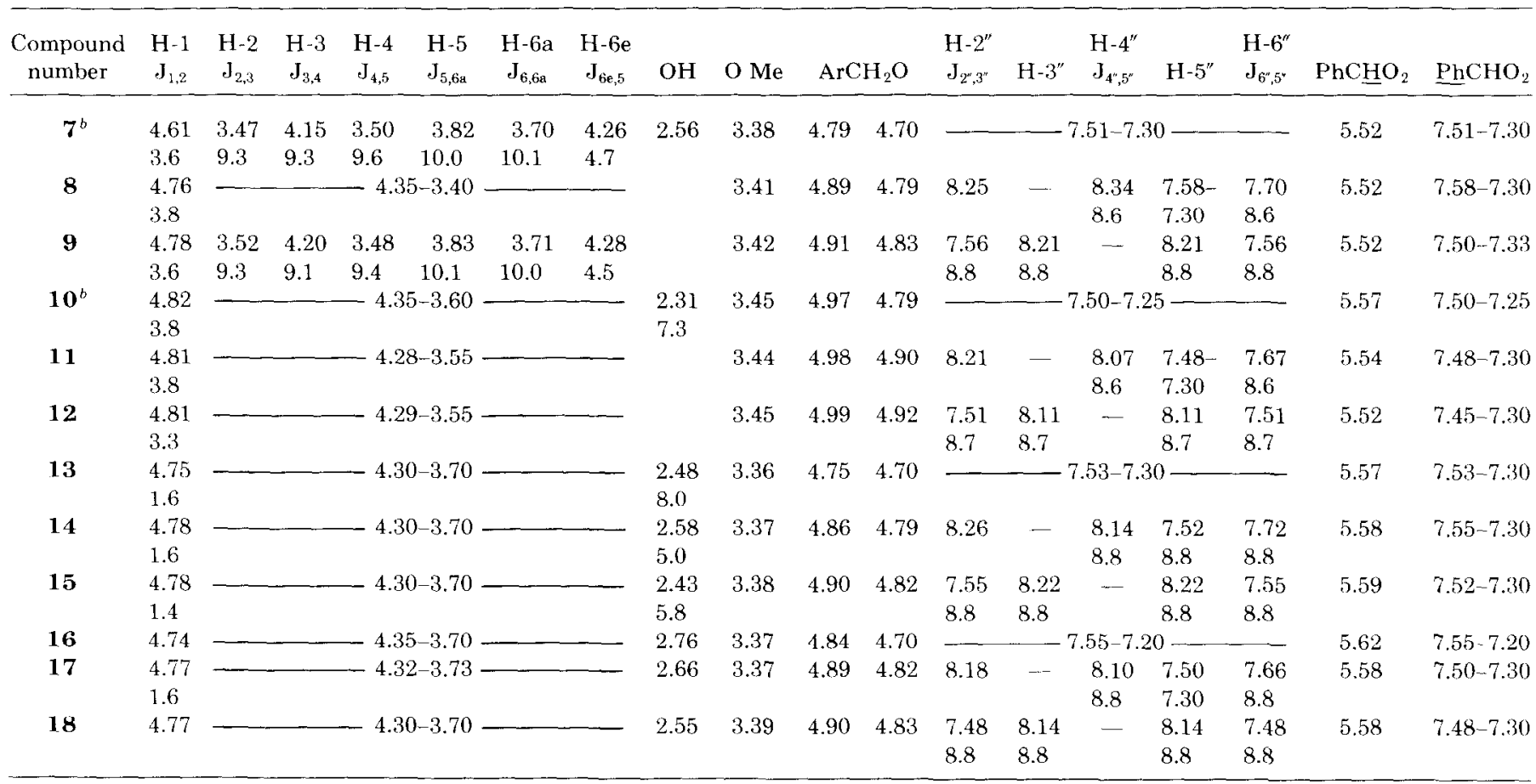

a All spectra were measured at $300 \mathrm{MHz}$ on $\mathrm{CDCl}_{3}$ solutions unless otherwise mentioned.

${ }^{b}$ Measured at $360 \mathrm{MHz}$.

the structure was also obtained from mass spectrometry. The chemical ionization mass spectrum of $\mathbf{2 4}$, methyl $3-O-(p$-nitrobenzyl)- $\alpha$-D-glucopyranoside showed the expected molecular ion peak at $m / z 347\left[\mathrm{M}+\mathrm{NH}_{4}^{+}\right]^{+}$. Periodate oxidation of $\mathbf{2 0}$, methyl 2- $O$ - $(m$-nitrobenzyl $)$ $\alpha$-D-glucopyranoside, and 23, methyl 3-O-(m-nitrobenzyl)- $\alpha$-D-glucopyranoside, was carried out according to the procedure of Avigad (11). Compound 20 consumed one equivalent of sodium periodate, whereas $\mathbf{2 3}$ did not react, thus providing unequivocal evidence that $\mathbf{2 0}$ and 23 are 2-O- and 3-O-isomers, respectively. Finally, methyl 2-Omethyl- $\alpha$-D-mannopyranoside (31) and methyl 3-Omethyl- $\alpha$-D-mannopyranoside (32) were prepared according to the procedure of Nashed (6).

Aqueous solutions of 5, 6, and 19-32 (7.5-40 mM) for hapten inhibition study were prepared by gentle warming and or vortexing. Quantitative precipitation of Con A by dextran B-1355-S, PSA by $S$. cerevisiae mannan, LCH by Pichia sp. or H. holstii phosphomannan, and VFA by $S$. cerevisiae mannan was carried out by adding increasing amounts of the polysaccharide to a fixed concentration of the lectin in suitable buffer solution (see Materials and Methods). Each of the compounds 5, 6, and 19-32 was assayed for its ability to inhibit the lectin precipitation reaction. Figures 2 and 3 show the typical inhibition curves obtained for LCH:phosphomannan sys- tem using 19-30 as haptens. The 50\% inhibition concentration $\left(\mathrm{IC}_{50}\right)$ values obtained from these curves for 19-30 were normalized with respect to that of the standard monosaccharide haptens, methyl $\alpha$-D-glc $p$ and methyl $\alpha$-D-man $p$ to give relative inhibitory potencies (see Tables IV and V). For comparison, the relative inhibitory potencies of 2-O-and 3-O-methyl derivatives of methyl $\alpha$-D-manp and 2-O- and 3-O-p-nitrobenzoyl derivatives of methyl $\alpha$-D-glcp are also listed in Tables IV and V.

The $p$-nitrobenzoyl derivatives 5 and 6 were poor inhibitors for both Con A and PSA. The 2-O- and 3-Omethyl derivatives of methyl $\alpha-\mathrm{D}$-manp, $\mathbf{3 1}$ and $\mathbf{3 2}$, were moderately more potent (2.4 and 6 times, respectively) than methyl $\alpha$-D-man $p$ for inhibiting the precipitation of PSA by $S$. cerevisiae mannan. All of the 2-O-benzyl and nitrobenzyl derivatives $\mathbf{1 9 - 2 1}$ and $\mathbf{2 5 - 2 7}$ were 1.3 to 16.7 times more inhibitory than the standards for all four lectins. The corresponding 3-O-isomers 22-24 and 2830 were much more potent ( 2.8 to 40.5 times) than the standards for PSA, LCH, and VFA but were essentially noninhibitors of Con $\mathrm{A}$.

\section{DISCUSSION}

Many legume lectins are known to possess at least three classes of nonpolar binding sites in addition to their car- 
TABLE III

${ }^{1} \mathrm{H}$ NMR Data for 19-30 ${ }^{a}$

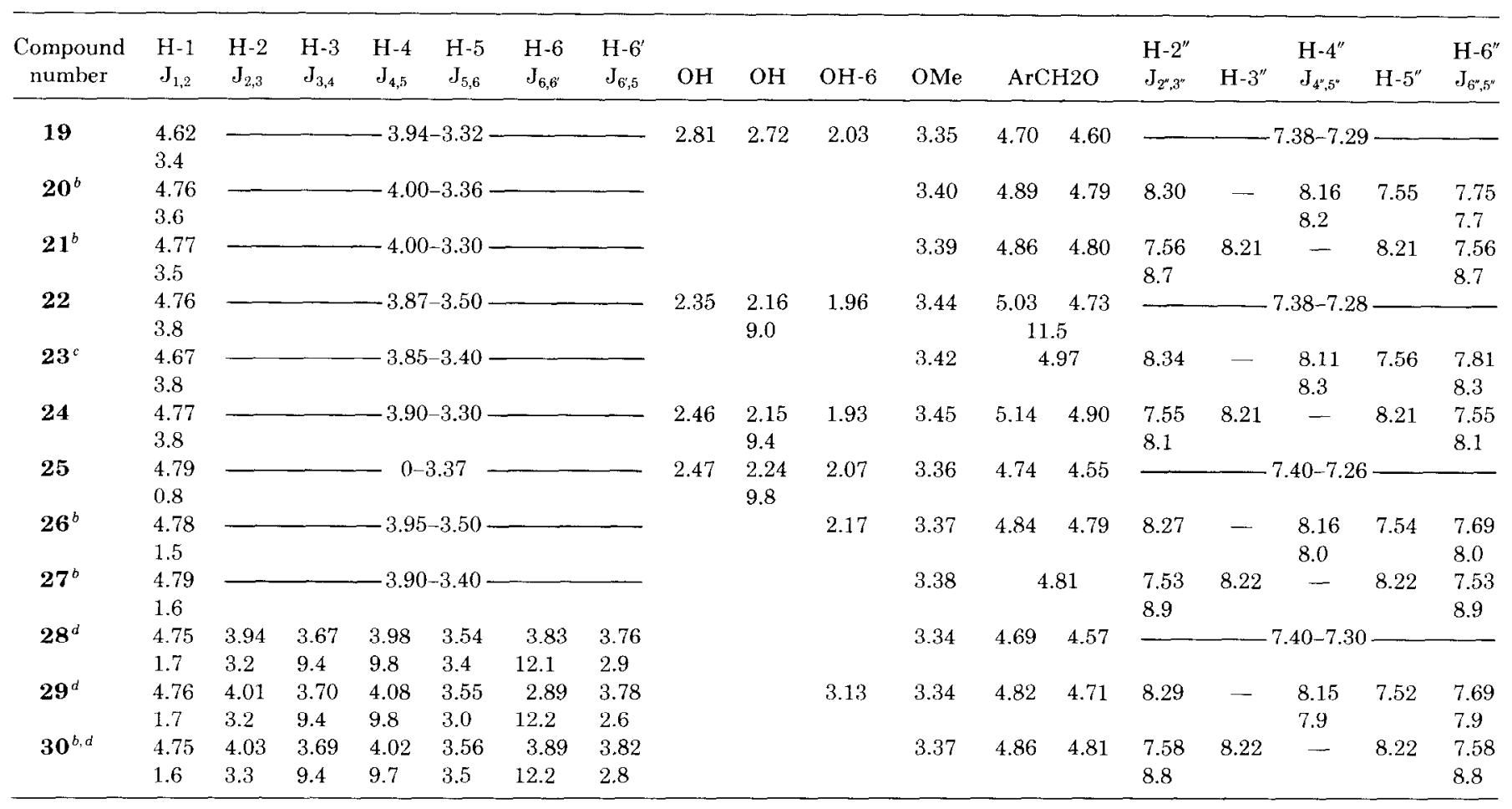

${ }^{a}$ All spectra were measured at $360 \mathrm{MHz}$ on $\mathrm{CDCl}_{3}$ solutions unless otherwise mentioned.

${ }^{b}$ Measured on $\mathrm{CDCl}_{3}$ solution containing traces of $\mathrm{CD}_{3} \mathrm{OD}$.

${ }^{c}$ Measured at $300 \mathrm{MHz}$ on $\mathrm{CD}_{3} \mathrm{OD}$ solution.

${ }^{d}$ Spectral data of $\mathrm{H}-1$ to $\mathrm{H}-6^{\prime}$ measured on $\mathrm{D}_{2} \mathrm{O}$ exchanged sample.

bohydrate and metal binding sites. Several legume lectins including lima bean lectin contain a specific, high-affinity binding site for adenine and its N-6 derivatives with association constants $10^{5}-10^{6} \mathrm{M}^{-1}$ (12). A low-affinity site that interacts with ligands such as tryptophan and in- doleacetic acid $\left(K_{\mathrm{a}} 10^{3}-10^{4} \mathrm{M}^{-1}\right)$ is present in each subunit of Con A and many other lectins (13). The third class involves a hydrophobic site present adjacent to the carbohydrate binding site. In Con A, this site interacts with the phenyl groups of phenyl $\beta$-glucosides and mannosides

TABLE IV

Hapten Inhibition by Methyl $\alpha$-D-Glucopyranoside and Derivatives

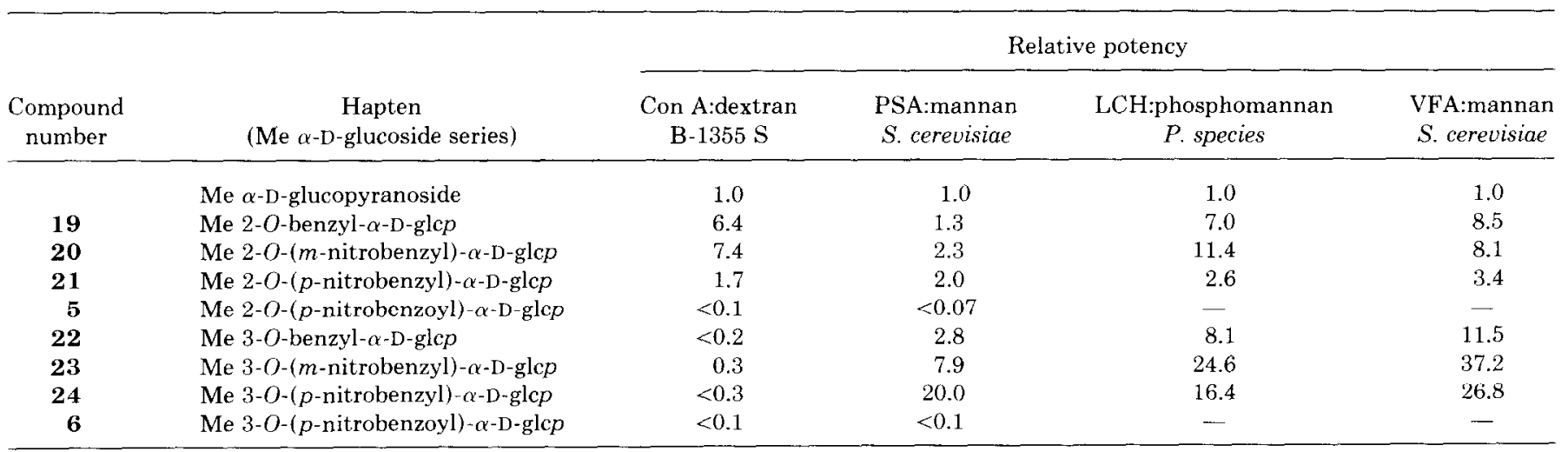


EXPLORING HYDROPHOBIC INTERACTIONS IN LEGUME LECTINS

TABLE V

Hapten Inhibition by Methyl $\alpha$-D-Mannopyranoside and Derivatives

\begin{tabular}{|c|c|c|c|c|c|}
\hline \multirow[b]{2}{*}{$\begin{array}{l}\text { Compound } \\
\text { number }\end{array}$} & \multirow[b]{2}{*}{$\begin{array}{c}\text { Hapten } \\
\text { (Me } \alpha \text {-D-mannoside series) }\end{array}$} & \multicolumn{4}{|c|}{ Relative potency } \\
\hline & & $\begin{array}{c}\text { Con A:dextran } \\
\text { B-1355 S }\end{array}$ & $\begin{array}{l}\text { PSA:mannan } \\
\text { S. cerevisiae }\end{array}$ & $\begin{array}{c}\text { LCH:phosphomannan } \\
\text { H. holstii }\end{array}$ & $\begin{array}{l}\text { VFA:mannan } \\
\text { S. cerevisiae }\end{array}$ \\
\hline & Me $\alpha$-D-mannopyranoside & 1.0 & 1.0 & 1.0 & 1.0 \\
\hline 25 & Me 2-O-benzyl- $\alpha$-D-manp & 4.0 & 2.8 & 8.8 & 3.9 \\
\hline 26 & Me 2-O-(m-nitrobenzyl $)-\alpha-\mathrm{D}-\operatorname{man} p$ & 5.9 & 5.0 & 16.7 & 5.4 \\
\hline 27 & Me 2-O-(p-nitrobenzyl $)-\alpha-\mathrm{D}-\operatorname{man} p$ & 3.7 & 2.7 & 1.0 .7 & 4.9 \\
\hline 31 & Me 2-O-methyl- $\alpha-\mathrm{D}-\operatorname{man} p$ & & 2.4 & - & 一 \\
\hline 28 & Me 3-O-benzyl- $\alpha$-D-man $p$ & 0.1 & 14.7 & 34.9 & 16.2 \\
\hline 29 & Me 3-U-(m-nitrobenzyl $)-\alpha-D-\operatorname{man} p$ & $<0.1$ & 13.2 & 40.5 & 17.2 \\
\hline 30 & Me 3-O-(p-nitrobenzyl $)-\alpha-$ - $-\operatorname{man} p$ & $<0.1$ & 13.6 & 32.0 & 15.2 \\
\hline 32 & Me 3-O-methyl- $\alpha$-D-manp & - & 6.0 & - & - \\
\hline
\end{tabular}

(14). On the other hand, the methyl groups of 3-O-methylD-glucose and the methylene group of 3-O-benzyl-D-glucose have been reported to interact at a similar site in PSA, LCH, and VFA but not with Con A (2). Until now, D-mannose derivatives carrying hydrophobic substituents at $\mathrm{C}-3$ position have not been examined.

In the present investigation we sought to obtain a better understanding of the site present in the legume lectins which interacts with hydrophobic ligands. A series of derivatives of methyl $\alpha$-D-glcp and methyl $\alpha$-D-manp containing 2-O- and 3-O-benzyl, $m$-nitrobenzyl, and $p$-nitrobenzyl substituents were synthesized according to the scheme shown in Fig. 1. The 2-O- and 3-O-methyl derivatives of methyl $\alpha$-D-man $p$ and 2-O- and 3-O-p-nitrobenzoyl derivatives (see Materials and Methods) of methyl $\alpha$-D-glc $p$ were also prepared as probes for elucidating the structural requirements for the hydrophobic ligands. Nitro substituents in the phenyl ring were chosen so that these compounds could serve as precursors for the preparation of azido derivatives for affinity labeling of these hydrophobic sites. The yield of the isolated intermediates 718 was moderate. ${ }^{1} \mathrm{H}$ NMR spectra of each of the intermediates 7-18 showed characteristic signals arising from aromatic ring protons, the methine proton of the benzylidene group $(5.52-5.62 \mathrm{ppm})$, the anomeric proton (4.61-4.82), and the glycosidic methyl protons (3.36-3.45). Sugar ring protons of 2-O-substituted compounds 7 and 9 exhibited well-resolved resonances and hence were amenable to complete spectral assignment, whereas the remainder of the derivatives 10-18 showed overlapping signals in the sugar ring proton region (see Table II). ${ }^{1} \mathrm{H}$ NMR spectrum of 9 provided convincing spectral evidence for its identity as methyl $2 O$ ( $p$-nitrobenzyl) $4,6-$ $O$-benzylidene- $\alpha$-D-glucopyranoside. Three resonances appearing at $\delta 4.78\left(\mathrm{~d}, 1 \mathrm{H}, J_{1,2}=3.6 \mathrm{~Hz}\right), 4.20(\mathrm{dt}, 1 \mathrm{H}$, $\left.J_{3,4}=9.1 \mathrm{~Hz}, J_{3,2}=9.3 \mathrm{~Hz}, J_{3, \mathrm{OH}}=1.8 \mathrm{~Hz}\right)$, and $3.52 \mathrm{ppm}$ $\left(\mathrm{dd}, 1 \mathrm{H}, J_{2,1}=3.6 \mathrm{~Hz}, J_{2,3}=9.3 \mathrm{~Hz}\right.$ ) were tentatively assigned to $\mathrm{H}-1, \mathrm{H}-3$, and $\mathrm{H}-2$, respectively. $\mathrm{On} \mathrm{D}_{2} \mathrm{O}$ exchange, the signal at $4.20 \mathrm{ppm}$ collapsed to a triplet and subsequent irradiation of the resonance at $4.78 \mathrm{ppm}$ resulted in the simplification of the signal at $3.52 \mathrm{ppm}$ into a doublet $\left(J_{2,3}=9.3 \mathrm{~Hz}\right)$, thus confirming the structural assignment. In contrast to compounds $\mathbf{7}$ and $\mathbf{9}$, the debenzylidenated 3-O-substituted derivatives 28-30 showed well-resolved sugar ring proton resonances. The identity of compounds 19-21, 25-27 and 22-24, 2830 as the 2-O- and 3-O-isomers, respectively, was also established unambiguously by periodate oxidation (11).

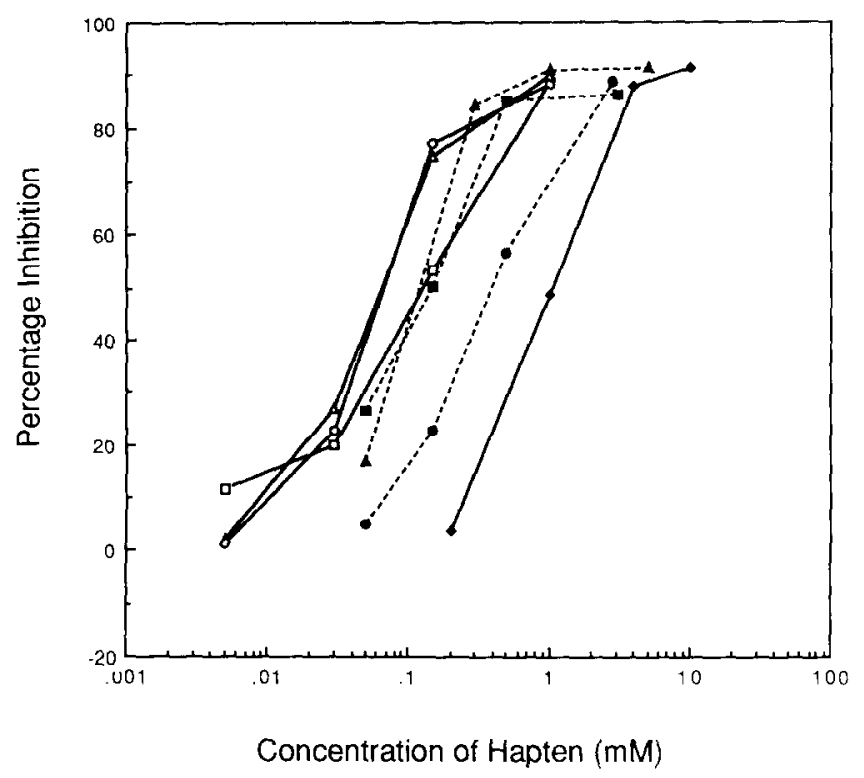

FIG. 2. Inhibition of lentil lectin (LCH)-Pichia sp. phosphomannan

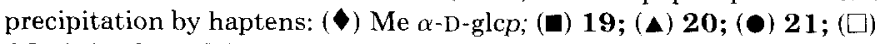
22; ( $\triangle$ ) 23; and (O) 24. Precipitation reaction vial contained $100 \mu \mathrm{g}$ of lentil lectin and $80 \mu \mathrm{g}$ of Pichia sp. phosphomannan. For details, see Materials and Methods. 


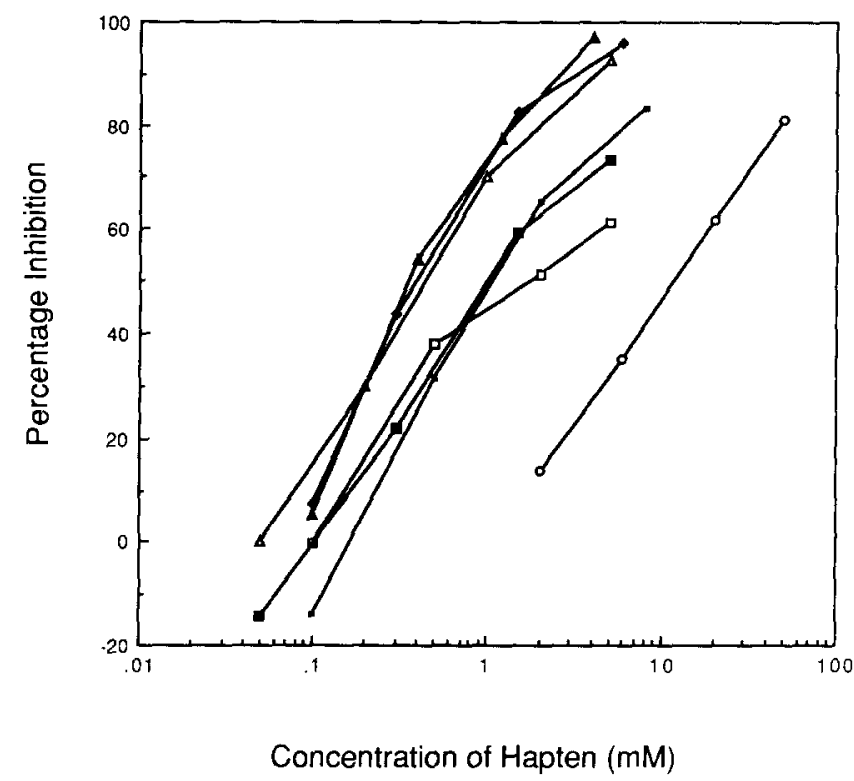

FIG. 3. Inhibition of lentil lectin (LCH)-Hansenula holstii phosphomannan precipitation by haptens: (O) Me $\alpha$-D-manp; ( $\square$ ) 25; (匹) 26;

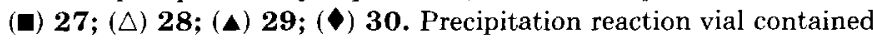
$100 \mu \mathrm{g}$ of lentil lectin and $100 \mu \mathrm{g}$ of Hansenula holstii phosphomannan. For details, see Materials and Methods.

Using a hapten inhibition of precipitation assay, we generated a complete set of inhibition curves and derived $\mathrm{IC}_{50}$ values for each derivative 5 and $6,19-30$, and 31 and 32 against each of the lectins, Con A, PSA, LCH, and VFA. An example of such a study is shown in Figs. 2 and 3 , which portray the effect of various $2-O$ - and $3-$ $O$-substituted derivatives $\mathbf{1 9 - 3 0}$ in the LCH:phosphomannan precipitation system. The most dramatic effect on this system is shown by substitution at the $O-3$ position of both methyl $\alpha$-D-glc $p$ and methyl $\alpha$-D-manp. Methyl 3-O-( $m$-nitrobenzyl)- $\alpha$-D-man $p$ was found to be 40 times more potent than the parent compound, methyl $\alpha$-Dmanp!

The hapten inhibition assay results summarized in Table IV and Table $\mathrm{V}$ indicate the following: (i) the presence of a methyl or methylene group at the O-2 or O-3 position of methyl $\alpha$-D-glc $p$ and methyl $\alpha$-D-manp is essential for hydrophobic interaction with PSA, LCH, and VFA; (ii) the substitution of methyl by benzyl leads to enhanced binding with the $m$-nitrobenzyl group contributing to maximum binding; and (iii) a ligand-protein hydrophobic interaction is also involved between Con $\mathrm{A}$ and 2-Omethyl, 2-O-benzyl, and 2-O-nitrobenzyl derivatives, resulting in greater binding, but the corresponding 3-O-isomers bind poorly due probably to steric hindrance.

These results may be rationalized on the basis of the recently published high-resolution $\mathrm{X}$-ray data of Con $\mathrm{A}$
(15) and VFA (16). As shown by Reeke and Becker (16), the replacement of two large side chains, Leu-99 and Arg228 , found in Con A with smaller groups, Ala-212 and Gly-100, in VFA results in a region of significant structural difference between these two lectins. Thus the considerably open carbohydrate binding site in VFA allows the binding of $\alpha$-D-glcp/ $\alpha$-D-manp derivatives with bulky substituents at the $\mathrm{O}-2$ and $\mathrm{O}-3$ positions unlike the situation with Con A. The two hydrophobic side chains Tyr101 and Trp-129 in VFA could interact by Van der Waal contacts with the benzyl groups of 19-30, leading to enhanced binding. Experiments are under way to prepare photoaffinity-labeled as well as spin-labeled derivatives based on the results of the present study in order to map the carbohydrate binding site in these legume lectins.

\section{ACKNOWLEDGMENTS}

We thank Willy J. Peumans for the supply of fava bean lectin, Mary J. Maliaric for technical assistance, and Valerie Amo for typing the tables.

\section{REFERENCES}

1. Goldstein, I. J., and Poretz, R. D. (1986) in Lectins: Properties, Functions and Applications in Biology and Medicine (Liener, I. E., Sharon, N., and Goldstein, I. J., Eds.), pp. 35-247, Academic Press, Orlando.

2. Allen, A. K., Desai, N. N., and Neuberger, A. (1976) Biochem. J. 155, 127-135.

3. Van Wauwe, J. P., Loontiens, F. G., and De Bruyne, C. K. (1975) Biochim. Biophys. Acta. 379, 456-461.

4. Buchanan, J. G., and Schwarz, J. C. P. (1962) J. Chem. Soc. 47704777.

5. Richtmyer, N. K. (1962) in Methods Carbohydrate Chemistry (Whistler, R. L., and Wolfrom, M. L., Eds.), pp. 107-108, Academic Press, New York.

6. Nashed, M. A. (1978) Carbohydr. Res. 60, 200-205.

7. Agrawal, B. B. L., and Goldstein, I. J. (1967) Biochim. Biophys. Acta. 147, 262-271.

8. Ishido, Y., Sakairi, N., Sekiya, M., and Nakazaki, N. (1981) Carbohydr. Res. 97, 51-79.

9. So, L. L., and Goldstein, I. J. (1967) J. Immunol. 99, 158-163.

10. Lowry, O. H., Rosebrough, N. J., Farr, A. L., and Randall, R. J. (1951) J. Biol. Chem. 193, 265-275.

11. Avigad, G. (1969) Carbohydr. Res. 11, 119-123.

12. Maliarik, M. J., and Goldstein, I. J. (1988) J. Biol. Chem. 263, 11274-11279.

13. Edelman, G. M., and Wang, J. L. (1978) J. Biol. Chem. 253, 30163022 .

14. Poretz, R. D., and Goldstein, I. J. (1971) Biochem. Pharmacol. 20, 2727-2739.

15. Derewenda, G. N., Jr., Yariv, J., Helliwell, J. R., Kalb (Gilboa), Dodson, E. J., Papiz, M. W., Wan, T., and Campbell, J. (1989) EMBO J. 8, 2189-2193.

16. Reeke, G. N., Jr., and Becker, J. W. (1988) Curr. Top. Microbiol. Immunol. 139, 35-58. 